\title{
ANÁLISE DA TEORIA DA CEGUEIRA DELIBERADA NO BRASIL
}

\author{
ANALYSIS OF THE WILFULL BLINDNESS THEORIE IN BRAZIL
}

ANÁLISIS DE LA TEORÍA CIEGO CIEGO EN BRASIL

\author{
Maria Carolina Carvalho de Almendra Freitas ${ }^{1}$ \\ José Laurindo de Souza Netto ${ }^{2}$ \\ Adriane Garcel ${ }^{3}$
}

\begin{abstract}
Resumo
O presente estudo visa investigar em que medida é possível aplicar-se a teoria da cegueira deliberada no Judiciário brasileiro. O objetivo deste artigo é analisar como os tribunais vem decidindo a respeito da teoria da cegueira deliberada. A metodologia eleita é através de revisão de literatura narrativa sobre essa temática. A contribuição deste artigo, portanto, foi analisar como se identifica o campo de aplicabilidade da teoria da cegueira deliberada em nosso ordenamento jurídico brasileiro. Os resultados encontrados foram no sentido de que é possível a aplicação da doutrina da cegueira deliberada em crimes ligados à operação lava jato.
\end{abstract}

Palavras-chave: ato ilícito; cegueira deliberada; dolo eventual.

\begin{abstract}
This study aims to investigate to what extent it is possible to apply the theory of deliberate blindness in the Brazilian judiciary. The purpose of this article is to analyze how the courts have

${ }^{1}$ Graduação em DIREITO pelo CENTRO DE ENSINO UNIFICADO DE TERESINA - CEUT (2003); ESPECIALIZAÇÃO em DIREITO PÚBLICO e em DIREITO PRIVADO pela UNIVERSIDADE FEDERAL DO PIAUÍ - UFPI (2004), MESTRADO em DIREITO INTERNACIONAL E ECONÔMICO pela UNIVERSIDADE CATÓLICA DE BRASÍLIA - UCB (2012); DOUTORANDA em DIREITO POLÍTICO E ECONÔMICO do programa de pós-graduação stricto sensu da UNIVERSIDADE PRESBITERIANA MACKENZIE - UPM. Profissinalmente atuou como advogada no escritório Moisés Reis Advogados Associados (2003-2005); Assessora da presidência no Tribunal Regional do Trabalho da 22a Região (2005-2007); Assessora da presidência do Conselho do Serviço de Apoio a Pequenas e Micro Empresas do Piauí - SEBRAE-PI (2015-2017); Professora substituta na Universidade Estadual do Piauí - UESPI (2010-2011), no Centro de Ensino Superior do Vale do Parnaíba - CESVALE (2010-2017) e na Faculdade Integral Diferencial - Facid Wyden (2016-2018).

2 Pós-doutor pela Faculdade de Direito da Universidade Degli Studi di Roma La Sapienza. Estágio de Pósdoutorado em Portugal e Espanha. Mestre e Doutor pela Universidade Federal do Paraná - UFPR.

3 Mestranda em Direito Empresarial e Cidadania no Centro Universitário de Curitiba - UNICURITIBA. Pósgraduada em Direito Aplicado pela Escola da Magistratura do Paraná - EMAP e FEMPAR.
\end{abstract}


been deciding on the theory of deliberate blindness. The chosen methodology is through a review of narrative literature on this topic. The contribution of this article, therefore, was to analyze how the field of applicability of the theory of deliberate blindness is identified in our Brazilian legal system. The results found were in the sense that it is possible to apply the doctrine of deliberate blindness in crimes linked to the lava jet operation.

Keywords: illegal act; deliberate blindness; eventual deception

\section{Resumen}

Este estudio tiene como objetivo investigar en qué medida es posible aplicar la teoría de la ceguera deliberada en el poder judicial brasileño. El propósito de este artículo es analizar cómo los tribunales han estado decidiendo sobre la teoría de la ceguera deliberada. La metodología elegida es a través de una revisión de la literatura narrativa sobre este tema. La contribución de este artículo, por lo tanto, fue analizar cómo se identifica el campo de aplicabilidad de la teoría de la ceguera deliberada en nuestro sistema legal brasileño. Los resultados encontrados fueron en el sentido de que es posible aplicar la doctrina de la ceguera deliberada en crímenes relacionados con la operación del chorro de lava.

Palabras clave: acto ilegal; ceguera deliberada; eventual fraude

\section{INTRODUÇÃO}

O direito tem sido a métrica para servir de ponto limítrofe no convívio em sociedade, procurando tal ciência e através das normas jurídicas, estabelecer comandos que se corporificam em regras éticas de conduta aos seus destinatários que coabitam em determinado meio social.

Antes do direito, existiam os costumes que eram seguidos pelos integrantes das glebas, tribos e clãs, sendo estes ordenamentos aplicados pelas autoridades da época. Em caso contrário, os infratores estavam sujeitos a sanções aplicadas pelos mais sábios que ocupavam a liderança ${ }^{4}$.

Inúmeras regras de ordem penal foram necessárias para que se buscasse o objetivo fim do direito que é a pacificação social e a convivência harmônica entre os entes de uma determinada Sociedade.

Feito este breve intróito, necessário destacar que o presente artigo procura conceituar o significado da chamada teoria da cegueira deliberada e avançar quanto à sua origem e surgimento no cenário jurídico norte americano e inglês, bem como na Espanha e no Brasil.

\footnotetext{
${ }^{4}$ Com base nas considerações lançadas na internet. Disponível em:< https://bigbluebook.org/pt/70/4/>. Acesso em: 30. jan. 2020. Além disso, maiores informações podem ser encontradas em:< https://pt.wikipedia.org/wiki/Cl\%C3\%A3> Acesso em: 30. Jan. 2020.
} 
Em seguimento, faremos uma análise prefacial do que vem a ser dolo eventual e culpabilidade no direito brasileiro, e após isso, faremos a análise propriamente dita da doutrina da teoria da cegueira deliberada no ordenamento jurídico brasileiro.

O método eleito será através de revisão bibliográfica narrativa, com a análise de artigos, dissertações e teses, na busca da contribuição científica do tema afeito à doutrina da teoria da cegueira deliberada.

Cabe destacar que um dos objetivos do presente artigo mira analisar como os tribunais vem decidindo a respeito da teoria da cegueira deliberada no ordenamento jurídico brasileiro, demonstrando quais são os posicionamentos doutrinários e da jurisprudência em torno desta temática.

Para que isso seja viabilizado, iremos nos aprofundar no âmbito de aplicabilidade dessa teoria da cegueira deliberada no ordenamento jurídico brasileiro, com a ancoragem específica nos Tribunais de Justiça, posicionando o ângulo da pesquisa no ramo específico do direito penal.

Para a realização do presente artigo foi escolhida a metodologia de Revisão de Literatura Narrativa, que segundo Rother "constituem, basicamente, de análise da literatura publicada em livros, artigos de revista impressas e/ou eletrônicas na interpretação e análise crítica pessoal do autor" (2007, p. 1). E ainda, para Rother, a revisão narrativa baseia-se:

[...] da aquisição e atualização de conhecimento sobre um determinado tema em curto período de tempo [...] para descrever o estado da arte de um assunto específico, sob o ponto de vista teórico ou contextual [...] da análise da literatura, da interpretação e análise crítica pessoal do pesquisador (2007, p. 9).

Estas revisões buscaram responder questionamentos relacionados a Cegueira Deliberada, tendo como palavras-chave "Teoria da Cegueira Deliberada" e "Ordenamento Jurídico Brasileiro", com uso de operadores booleanos AND quando necessário.

Não houve a determinação de um recorte temporal, já que todos os artigos e publicações a respeito do assunto poderiam interessar e ainda, sem determinação de recorte geográfico, vinculando somente que as publicações escolhidas deveriam ser em relação a realidade jurídica brasileira, ou, outras publicações que pudessem colaborar com o embasamento teórico deste artigo. 


\section{TEORIA DA CEGUEIRA DELIBERADA: BREVE HISTÓRICO E ANÁLISE CONCEITUAL}

Damos início as discussões deste artigo elucidando o significado da teoria da cegueira deliberada, primeiramente trazendo a conceituação dessa teoria e um breve posicionamento histórico quanto ao surgimento deste instituto.

Para estabelecermos o conceito da teoria da cegueira deliberada nos apoiamos na balizada doutrina de Cardoso (2018, p. 1350), que define a referida teoria como sendo aquela na qual o "[...]agente cria voluntariamente uma barreira psicológica que o impede de ver circunstâncias óbvias, optando por permanecer na ignorância da realidade."

De acordo com Moser (2017), a teoria da cegueira deliberada (Wilfull Blindness Doctrine) também é conhecida como Doutrina das Instruções do Avestruz (Ostrich Instructions) ou ainda, ignorância deliberada como é conhecida no Direito Espanhol.

De forma didática, Moser (2017, p. 167), é categórica ao explicar que: “Daí surgiu o nome "Instruções do Avestruz", uma vez que o agente, assim como o avestruz, enfia sua cabeça na terra, deixando de enxergar as coisas ao seu redor e evitando, assim, tomar conhecimento dos fatos."

A mesma articulista traz luz à ampla aceitação da doutrina da cegueira deliberada em países como Estados Unidos da América e Inglaterra baseada no motivo de que, como se alinham ao common law, inexiste a figura do dolo eventual, ao contrário do que ocorre em nosso ordenamento jurídico pátrio.

Estabelecido o conceito dessa temática, revela-se necessário apresentarmos uma ordem cronológica $^{5}$ quanto ao surgimento deste instituto, o que foi brilhantemente explicitado na monografia articulada por Gehr (2012, p. 3), a qual transcrevemos algumas considerações a respeito da teoria da cegueira deliberada:

\footnotetext{
${ }^{5}$ Interessante referência histórica feita por Gehr (2012, p. 3), merece destaque em nota de rodapé ao destacar a monografista que: "Em 1899, pela primeira vez, a teoria da willful blindness foi apreciada na Suprema Corte norteamericana, no caso Spurr vs. United States4, em que se revisava a condenação de Spurr, presidente do Commercial National Bank of Nashville, condenado por ter certificado diversos cheques emitidos por um cliente cuja conta carecia de fundos. A lei aplicável dispõe que para que tal conduta possa ser sancionada penalmente é necessária uma violação intencionada dos preceitos que regulam a emissão de cheques. O Tribunal Supremo entendeu que se um oficial certifica cheques com a intenção de que o emissor obtenha dinheiro do banco, em que pese não haver fundos, tal certificação não só é ilícita como pode ser imputado a ele o propósito de violar a lei. Essa "má intenção" pode ser presumida quando o oficial se mantém deliberadamente na ignorância acerca da existência de fundos na conta em questão, ou quando mostra grande indiferença a respeito de seu dever de se assegurar acerca desta circunstância.
} 
A primeira vez que se equiparou, no plano Judiciário, o conhecimento e a cegueira deliberada foi em 1861, no caso Regina vs. Sleep, no qual se revisava a condenação de um sujeito acusado de gestão ruinosa, infração esta que requer o conhecimento por parte do autor de que se trata de bens de titularidade estatal. Sleep entregou para que fosse embarcado em um navio um barril que continha parafusos de cobre, alguns dos quais marcados com um sinal em forma de flecha que indicava que eram de propriedade estatal. Condenado em primeiro grau, recorreu alegando não ter consciência de que se tratava de um bem estatal, e o juiz decidiu revogar sua condenação já que o Júri não considerou que o agente sabia que os bens estavam marcados, nem que se abstivera intencionalmente de obter este conhecimento. A partir deste entendimento pode-se concluir que, caso restasse comprovada a intenção do indivíduo de abster-se, mereceria ele uma resposta punitiva semelhante à dada em caso do conhecimento certo. Com base neste primeiro julgado desenvolveu-se a chamada willful blindness. As decisões que se seguiram, ressalte-se, não esclarecem se para aplicar a equiparação sustentada no procedente citado é necessário demonstrar que o sujeito suspeitava, quando menos, da possibilidade de uma atividade ilícita, ou se esta equiparação só poderia ser utilizada às alegações de desconhecimento absolutamente inverossímeis por parte de alguns acusados. Fato é que no final do século XIX a referida equiparação estava amplamente assentada na doutrina inglesa.

De acordo com Robbins (1990, p. 191-234, apud KLEIN, nd, p. 2), é possível estabelecermos um ponto de partida para a aplicação da doutrina da teoria da cegueira deliberada através da contribuição de Robbins e de Klein, que é profundamente enriquecedora ao posicionar no eixo cronológico da seguinte forma:

Segundo Ira P. Robbins, a Doutrina da Cegueira Deliberada começou a dar seus primeiros passos nos Tribunais ingleses em 1861, no caso Regina $v$. Sleep. Sleep era um ferrageiro, que embarcou em um navio contêiners com parafusos de cobre, alguns dos quais continham a marca de propriedade do Estado inglês. $\mathrm{O}$ acusado foi considerado culpado pelo júri por desvio de bens públicos - infração esta que requeria conhecimento por parte do sujeito ativo. Ante a arguição da defesa do réu, de que não sabia que os bens pertenciam ao Estado, Sleep foi absolvido pelo juiz, sob a justificação de que não restou provado que o réu tinha deveras conhecimento da origem dos bens, bem como não houve prova de que Sleep se abstivera de obter tal conhecimento.

Do exemplo acima, embora remonte a 1861 e já estejamos na segunda década do século XXI, é perceptível a viés extremamente legalista do direito inglês baseado no common law ${ }^{6}$.

\footnotetext{
${ }^{6}$ Para maiores noções básicas a respeito do que vem a ser o common law, remetemos o leitor ao seguinte endereço eletrônico nos sítios da internet: Disponível em: $<$ https://www.conteudojuridico.com.br/consulta/artigos/40743/odireito-ingles>. Acesso em: 01. fev. 2020.
} 


\title{
3.1 Da necessária abordagem conceitual da culpabilidade e do dolo eventual: aspectos predicamentais para a abordagem da doutrina da cegueira deliberada no brasil
}

Para que a abordagem a respeito da doutrina da teoria da cegueira deliberada seja profícua e eficiente, necessário que sejam retomados dois conceitos primordiais que permitiram a compreensão do núcleo de especificação que gira em torno da doutrina da cegueira deliberada no ordenamento jurídico brasileiro.

De acordo com as reflexões de Ricardo (2018, p. 238), extremamente clareadora a diferenciação entre as modalidades de culpa consciente e inconsciente, a seguir reproduzidas:

\begin{abstract}
Embora o Código Penal não tenha a previsão nesse sentido, existem duas espécies de culpa amplamente discutidas pela melhor doutrina. A primeira é a culpa inconsciente (sem representação), que é a ação sem previsão do resultado previsível, a também chamada de "culpa ex ignorantia". Ou seja, aqui o sujeito ativo atua sem representar o perigo existente em sua conduta. Embora exista a possibilidade de previsão do resultado, o agente deixa de prevê-lo por desatenção ou mesmo desleixo. A segunda é a culpa consciente (com representação), também chamada de culpa com previsão. Aqui o sujeito ativo sabe do perigo presente em sua conduta, ou seja, existe a previsibilidade, contudo este age com inobservância de seu dever de cuidado, acreditando fielmente que o resultado não se concretizará.
\end{abstract}

O mesmo autor ainda destaca que no dolo eventual podemos entender que o agente, embora preveja o resultado, aceita o risco de sua produção. Todavia, no que se refere à culpa consciente, a situação é um pouco diferente, na medida em que o agente prevê, de toda sorte, ele acredita sinceramente na sua não ocorrência, de modo que não assume o risco, sendo certo que caso acreditasse na produção do resultado, teria deixado de praticar a conduta.

Bittencourt, por sua vez, busca diferenciar o dolo eventual da culpa consciente nos apresentando a seguinte explicação doutrinária:

[...] a distinção entre dolo eventual e culpa consciente resume-se à aceitação ou rejeição da possibilidade de produção do resultado. Persistindo a dúvida entre um e outra, dever-se-á concluir pela solução menos grave, qual seja pela culpa consciente, embora, equivocadamente, não seja essa a orientação adotada na práxis forense (2014, p. 386).

Para Zaffaroni, Juarez Cirino dos Santos e Fernando Galvão, buscamos uma preciosa definição para a figura do dolo eventual, apresentada da seguinte forma: 
Os crimes que se realizam com dolo eventual admitem tentativa [...] Se o dolo eventual é caracterizado pela postura subjetiva de assumir a ocorrência do resultado, o comportamento é tendencioso à realização de tal objetivo e pode haver a interrupção que autoriza uma responsabilidade diminuída. É certo que o resultado jurídico exigido pelo dolo eventual deve ser determinado.

Para Aníbal Bruno (apud Dotti, 2012, não paginado), é oportuna a diferenciação existente entre dolo eventual e culpa consciente na medida em que:

\begin{abstract}
A forma típica da culpa é a culpa inconsciente, em que o resultado previsível não é previsto pelo agente. É a culpa sem previsão. Ao lado desta, construiu a doutrina a chamada culpa consciente, em que o resultado é previsto pelo agente, embora este sinceramente espere que ele não aconteça. A culpa com previsão representa um passo mais de culpa simples para o dolo. É uma linha quase imponderável que a delimita do dolo eventual. Neste, o agente não quer o resultado, mas aceita o risco de produzi-lo. Na culpa com previsão, nem esta aceitação do risco existe, o agente espera que o evento não ocorra.
\end{abstract}

Nos ensinamentos profícuos de René Dotti, a diferenciação entre culpa consciente e dolo eventual se traduz na medida em que a caracterização do dolo eventual exige, por parte do agente, uma ratificação prévia, uma anuência ao seu evento. É elementar a necessidade desse elemento subjetivo, pois em caso contrário a conduta caracterizaria a culpa consciente, definida como a culpa com previsão.

Dessa forma e estabelecidas estas diferenciações necessárias com arrimo na abalizada doutrina acima referenciada, sentimo-nos mais tranquilos em buscar analisar a doutrina da teoria da cegueira deliberada com o preparo exigido para tal mister.

\title{
3 A TEORIA DA CEGUEIRA DELIBERADA NO DIREITO ESPANHOL
}

Conquanto no direito espanhol exista uma inclinação no que pertine a utilização da teoria da cegueira deliberada, é salutar até mesmo em respeito à dialética, destacarmos um posicionamento contrário do entendimento do Supremo Tribunal Espanhol (STE) que vem se inclinando pela aplicabilidade desta doutrina desde 2000 .

Nesta ordem de ideias, cabe salientar que, no tribunal espanhol existe um caso emblemático em franca oposição à aplicação da teoria da cegueira deliberada, referenciado por Moser (2017, p. 168), que merece a devida transcrição por se tratar de exceção da sentença 797 de 20 de julho de 2006, proferida pelo relator Enrique Bacigalupo Zapater, integrante da $2^{\mathrm{a}}$ Turma do Tribunal Supremo na justificativa de voto vencido, nos seguintes termos: 
Em sua decisão, esse julgador afirmou que aquele que se coloca intencionalmente em situação de ignorância, na verdade, sabe o que ignora, de modo que o nome utilizado, "cegueira deliberada", é insustentável e contraditório, bem como a respectiva Teoria é desnecessária para se condenar alguém por um delito doloso, conforme se observa deste trecho: $\mathrm{O}$ simples fato de se empregar familiares com vínculos estreitos, como o filho, a esposa e a nora, no procedimento, revela se tratar de assuntos que se deseja não seja conhecidos por estranhos e que se desconfia que outras pessoas com vínculo puramente profissional possam obter informações a respeito. Sem sombra de dúvidas, o recorrente tinha este conhecimento cotidiano e sabia que a esposa do seu pai e sua própria esposa realizavam operações semelhantes, bem como outros íntimos de seu pai. Com base nestes fatos, o Juiz disse não ter dúvidas sobre a existência de dolo direto deste recorrente e de outros que se encontravam em situação similar, descartando que tenham agido com imprudência grave (questão relevante aos efeitos da possível aplicação do art. 303.3 CP). Neste contexto, fez-se referência a uma doutrina do procedimento legal dos EUA, segundo a qual se trataria de casos de "ignorância deliberada" ou de "ignorância intencional". Tais expressões não são nem idiomáticas nem conceitualmente adequadas, uma vez que, se tem a intenção de ignorar é porque, na realidade sabe-se que se ignora. Ninguém pode ter intenção do que não sabe. A contradição, literalmente falando, é evidente. Sem prejuízo disso, a estimação do dolo é, no resultado, correta, uma vez que, como frisado o Júri com frequência, aquele sobre cujas ações a suspeita delitiva é claramente difundida entre pessoas sem nenhuma formação especial, omite tomar medidas para não realizar o tipo penal, age com indiferença e, para tanto, com dolo, porque frente a possibilidade de realização do tipo, de todas as maneiras, há agido.

Importante ressaltar que o voto vencido acima reflete um importante posicionamento jurídico do Magistrado que o proferiu, na medida em que teceu relevantes e judiciosas considerações acerca das falhas existentes na aplicabilidade desta teoria da cegueira deliberada, porquanto sinaliza no sentido de "ninguém pode ter intenção do que não sabe" (Moser, 2017, p. 168), o que coloca em xeque a viabilidade de tal instituto.

\section{DA TEORIA DA CEGUEIRA DELIBERADA NO BRASIL: SURGIMENTO E CONTROVÉRSIAS DOUTRINÁRIAS}

Na mesma linha de raciocínio, podemos ressaltar que a teoria da cegueira deliberada teria surgido no Brasil por meio de um caso que tomou repercussão nacional em razão de um furto do Banco Central de Fortaleza ${ }^{7}$ e que, por essa razão, a referida teoria encontrou seu

\footnotetext{
${ }^{7}$ Interessante a narrativa do caso feita por Ricardo (2018, p. 244) que vale pela riqueza histórica para o surgimento da teoria da cegueira deliberada, narrada da seguinte forma: "O primeiro caso emblemático em que se aplicou a Willful Blindness Doctrine foi o assalto ao Banco Central do Brasil, que ocorreu na cidade de Fortaleza, no Ceará. Em primeira instância, o Juiz Federal Danilo Fontenelle Sampaio utilizou-se da referida teoria para fundamentar
} 
destaque no ordenamento jurídico pátrio, sendo alvo de cobrança em concursos jurídicos ${ }^{8}$ (KLEIN, nd ${ }^{9}$, p. 2).

Em razão de seu posicionamento de vanguarda, o Tribunal de Justiça do Estado do Paraná (TJPR) já se manifestou reiteradas vezes ${ }^{10}$ a respeito da doutrina da teoria da cegueira deliberada.

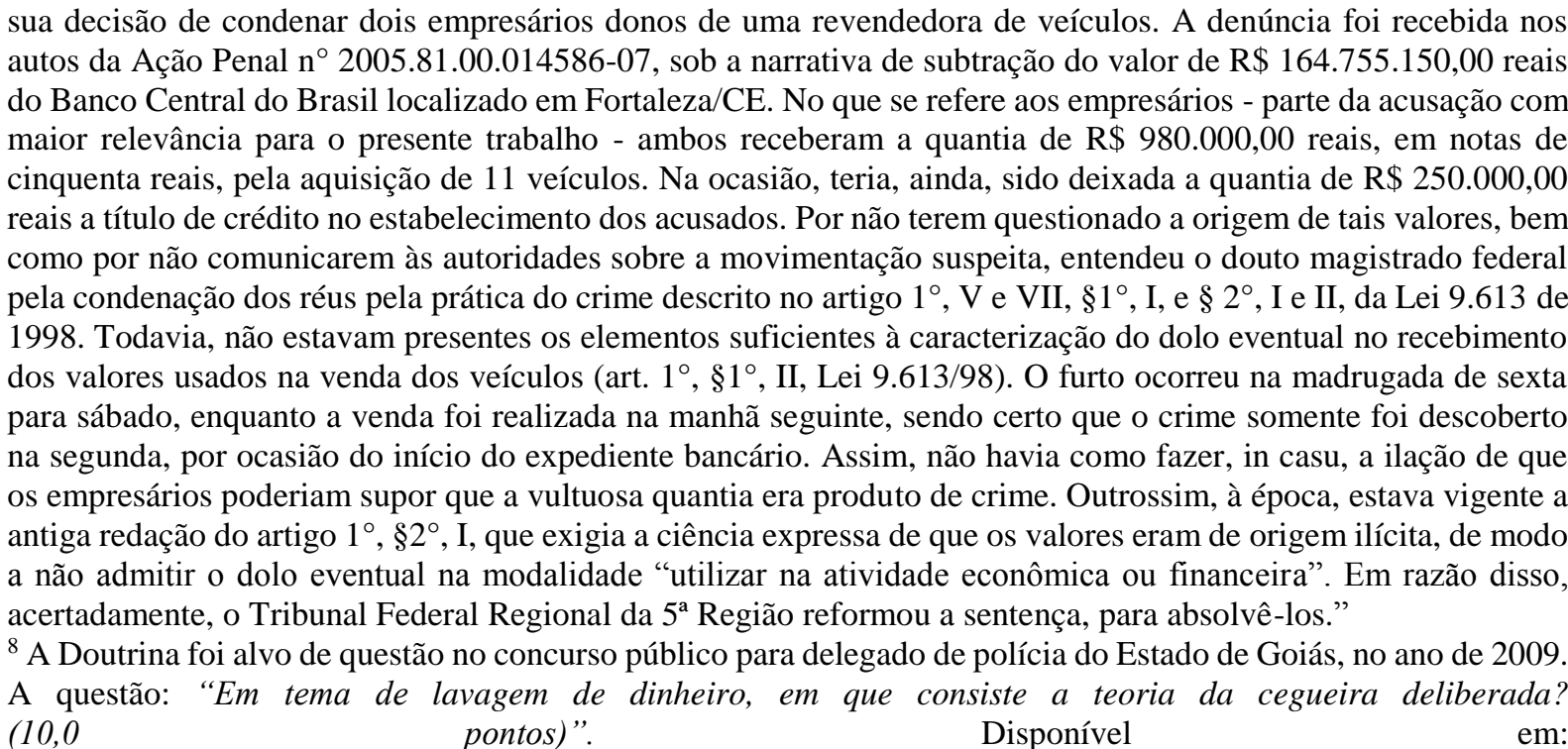
<http://www.vestibular.ueg.br/PDFs/concursos/110/provas/Prova\%20Delegado-

2\%C2\%AA\%20etapaGrupo\%20I.ZIP>. Acesso em: 03. fev. 2020.

${ }^{9}$ Esclarecemos que a fonte desta pesquisa pode ser encontrada no seguinte endereço eletrônico: Disponível em:< http://editora.pucrs.br/anais/cienciascriminais/III/4.pdf>. Acesso em: 01. fev. 2020.

${ }^{10}$ Nesse sentido, o recente julgado proferido pela E. $4^{\text {a }}$ Câmara Cível do TJPR, nos seguintes termos: DIREITO ADMINISTRATIVO. APELAÇÃO CÍVEL. AÇÃO CIVIL POR IMPROBIDADE ADMINISTRATIVA. PRELIMINAR DE NULIDADE DO PROCEDIMENTO PREPARATÓRIO POR EXCESSO DE PRAZO E POR AUSÊNCIA DE PUBLICIDADE. NÃO ACOLHIMENTO. PRAZO DE CONCLUSÃO IMPRÓPRIO AO MINISTÉRIO PÚBLICO. ENTENDIMENTO DO SUPERIOR TRIBUNAL DE JUSTIÇA. AUSÊNCIA DE PUBLICAÇÃO DE ATOS DO PROCEDIMENTO PREPARATÓRIO QUE NÃO REPERCUTE EM NULIDADE DO PROCESSO JUDICIAL. FASE MERAMENTE INVESTIGATIVA QUE, INCLUSIVE, PERMITE O DIFERIMENTO DO CONTRADITÓRIO. PRELIMINAR DE AUSÊNCIA DE INDIVIDUALIZAÇÃO DAS CONDUTAS. REJEIÇÃO. SENTENÇA DEVIDAMENTE FUNDAMENTADA. QUESTÃO DE FUNDO. CONTRATAÇÃO DE SERVIÇO DE TRANSPORTE (VAN) COM O OBJETIVO DE LEVAR OS SERVIDORES, EM DUAS OCASIÕES, PARA CURSOS DE APERFEIÇOAMENTO. TESE ACUSATÓRIA. CONTRATAÇÃO DIRETA E VERBAL REALIZADA PARA FAVORECER O AGENTE QUE TRABALHOU NA CAMPANHA ELEITORAL. DOLO NÃO DEMONSTRADO. DEPOIMENTOS COLHIDOS EM AUDIÊNCIA CONTRADITÓRIOS. IRREGULARIDADES PROCEDIMENTAIS QUE NÃO COMPROVAM, POR SI SÓ, A MÁ-FÉ. MERA INABILIDADE DA ADMINISTRAÇÃO. AGENTES QUE ACREDITARAM AGIR AMPARADOS PELA EXCEÇÃO CONSTANTE NO ARTIGO 60, PARÁGRAFO ÚNICO, DA LEI N.․ 8.666/93, QUE PERMITE CONTRATAÇÃO VERBAL EM AQUISIÇÕES DE BAIXÍSSIMO CUSTO. TEORIA DA CEGUEIRA DELIBERADA. INAPLICABILIDADE À ESPÉCIE. ANÁLISE DE MÉRITO QUE, AO CONTRÁRIO DA FASE INICIAL DA AÇÃO POR IMPROBIDADE ADMINISTRATIVA, ATRAI A APLICAÇÃO DO PRINCÍPIO IN DUBIO PRO REO. ADEMAIS, AUSÊNCIA DE PREJUÍZO AO ERÁRIO, ANTE A DEVOLUÇÃO INTEGRAL DOS VALORES DECORRENTES DA CONTRATAÇÃO. APELOS DOS REQUERIDOS PROVIDOS.APELO DO MINISTÉRIO PÚBLICO DESPROVIDO. I. O prazo para conclusão de procedimento preparatório pelo Ministério Público é impróprio e sua inobservância não acarreta desdobramentos no processo judicial. II. A não publicação de atos na imprensa sobre o procedimento preparatório não implica em ofensa à publicidade, pois sequer o contraditório é exigido nessa etapa, que é diferido para a fase processual consoante o teor do Enunciado n. ${ }^{o} 24$ das c. $4^{\mathrm{a}}$. e $5^{\mathrm{a}}$. Câmaras Cíveis do Tribunal de Justiça do Estado do Paraná: "No inquérito civil ou em qualquer outro procedimento 
Em razão da necessidade da verificação do estado da arte para refinamento do aludido estudo, insta ressaltarmos, ainda que com brevidade, a ratio decidendi vergastada no julgado ementado na nota 10 (nota de rodapé 10).

Partindo-se dessa premissa, imperioso destacar o ápice do julgado da lavra do E. Desembargador Relator Abraham Lincoln Calixto ao analisar o caso concreto por meio do qual firmou-se o entendimento de que:

[...] não se vislumbra a incidência da mesma à espécie, haja vista que o prefeito, ao autorizar os pagamentos apenas realizou expedientes normais do cargo, nada havendo no caderno processual que comprove alguma atitude deliberada no sentido de se omitir da realidade. VI. A ação de improbidade administrativa exige prova certa, determinada e concreta dos atos ilícitos e dos respectivos elementos que compõem o dolo para ensejar condenação. Não se contenta com simples indícios, nem com a verdade formal.

Em análise dialética, colhemos o posicionamento antagônico apresentado por ao obtemperar que:

\begin{abstract}
A literatura penal e a jurisprudência brasileiras têm admitido, por interpretação analógica, a aplicação a teoria norte-americana da cegueira deliberada (wilfull blindness, deliberatte ignnorance ou ainda conscious avoidance doctrine) e igualado este grau de culpabilidade ao pátrio dolo eventual, especialmente nos crimes de lavagem de dinheiro. Em uma breve síntese, a doutrina cegueira deliberada é uma construção jurisprudencial que iguala à conduta dolosa àquela do autor que propositalmente se coloca em situação de erro de tipo, ou seja "o agente que pretende o tipo objetivo ignorando algumas peculiaridades do caso concreto por ter se colocado voluntariamente numa posição de alienação diante de situações suspeitas, procurando não se aprofundar no conhecimento das circunstâncias objetivas. A ignorância deliberada trata, portanto, de um estado mental peculiar: o autor
\end{abstract}

investigatório não é de rigor a observância do contraditório e da ampla defesa, pois apenas constituem meios de natureza inquisitória destinados a formar a convicção do Ministério Público acerca da existência ou não de elementos indiciários tendentes à deflagração da ação civil pública". III. Não há que se falar no caso concreto em afronta ao princípio da individualização, porquanto a $\mathrm{r}$. decisão objurgada procedeu à correta e minudente apreciação das condutas imputadas a cada réu, inclusive analisando as respectivas provas produzidas nos autos. Se em dado momento da fundamentação houve identidade de argumentos, é porque, evidentemente, há similitude na forma de agir dos agentes. IV. No mérito, o ato de improbidade administrativa deve traduzir, necessariamente, a desonestidade, a conduta reprovável, a imoralidade, não se exaurindo pela mera ilegalidade decorrente da inabilidade ou da gestão imperfeita do administrador. V. No que tange à teoria da cegueira deliberada, onde o "agente cria voluntariamente uma barreira psicológica que o impede de ver circunstâncias óbvias, optando por permanecer na ignorância da realidade" (FRANCISCO DE ASSIS MACHADO CARDOSO, in Leis Penais Especiais, Editora Juspodivm, Salvador, 2018, pg. 1.350), não se vislumbra a incidência da mesma à espécie, haja vista que o prefeito, ao autorizar os pagamentos apenas realizou expedientes normais do cargo, nada havendo no caderno processual que comprove alguma atitude deliberada no sentido de se omitir da realidade. VI. A ação de improbidade administrativa exige prova certa, determinada e concreta dos atos ilícitos e dos respectivos elementos que compõem o dolo para ensejar condenação. Não se contenta com simples indícios, nem com a verdade formal. (TJPR - $4^{\text {a }}$ C. Cível - 0008864-39.2015.8.16.0112 - Marechal Cândido Rondon - Rel.: Desembargador Abraham Lincoln Calixto - J. 06.08.2019). Disponível em:< https://www.tjpr.jus.br/jurisprudencia>. Acesso em: 02 . fev. 2020 . 
possui uma deliberada indiferença diante de uma situação criminosa prévia (CARVALHO, 2015, p. 70-71).

Outra ementa oriunda do Tribunal de Justiça do Estado de Minas Gerais (TJMG) adota posicionamento favorável à aplicação ao caso sub judice da doutrina da teoria da cegueira deliberada, motivo pelo qual nos permitimos a transcrevê-la, de modo a reforçar a visão do leitor a respeito da temática trazida a exame:

EMENTA: APELAÇÃO CRIMINAL - TRÁFICO DE DROGAS SENTENÇA ABSOLUTÓRIA - RECURSO MINISTERIAL MATERIALIDADE E AUTORIA COMPROVADAS - TEORIA DA CEGUEIRA DELIBERADA - CONDENAÇÃO - NECESSIDADE PRESCRIÇÃO - OCORRÊNCIA - EXTINÇÃO DA PUNIBILIDADE. - Havendo nos autos elementos suficientes para se imputar a ré a autoria do crime de tráfico de drogas, a condenação é medida que se impõe. - É relevante pontuar que, segundo a teoria da cegueira deliberada, não fica eximido da responsabilidade o agente que ignora voluntariamente o próprio envolvimento em negócios escusos ou ilícitos. - O conjunto probatório evidencia que a acusada sabia e permitia que em sua residência ocorresse a comercialização de drogas, inclusive por adolescentes. - Decorrido o prazo prescricional entre a data do recebimento da denúncia até a do julgamento do presente acórdão condenatório, impõe-se declarar a extinção da punibilidade da apelada, pela prescrição da pretensão punitiva estatal. (TJMG - Apelação Criminal 1.0699.13.009524-2/001, Relator(a): Des.(a) Agostinho Gomes de Azevedo, $7^{\text {a }}$ CÂMARA CRIMINAL, julgamento em 13/02/2019, publicação da súmula em 22/02/2019)

Esclarecedora a ementa supra, porquanto a Sétima Câmara Criminal do TJMG entendeu pela condenação do réu na medida em que este teria buscado se utilizar de uma ignorância voluntária de modo a tentar ver aplicada ao caso concreto a doutrina da teoria da cegueira deliberada, o que foi repelida pela Egrégia Câmara Criminal.

Na mesma temática, a doutrina brasileira ao tratar do crime de lavagem de dinheiro, iguala o conhecimento potencial da cegueira deliberada (wilfull blindness) ao dolo eventual, justamente porque tais construções em torno da cegueira deliberada assemelham-se, de certa forma, ao dolo eventual da legislação e doutrina brasileira. Por isso e considerando a previsão genérica do art. 18, I, do CP, e a falta de disposição legal específica na lei de lavagem contra a admissão do dolo eventual, podem elas ser traduzidas para a nossa prática jurídica (MORO, 2010).

No que se refere a aplicação da doutrina da teoria da cegueira deliberada nos Estados Unidos da América, Moro (2010) traz à colação o caso United States vc. Cambell, no que tange ao delito de lavagem de capitais, a seguir transcrito: 


\begin{abstract}
Moro cita como exemplo da aplicação da Doutrina ao delito de lavagem de capitais, o case United States vs. Campbell, datado de 1992.Ellen Campbell, corretora de imóveis, teria vendido a Lawing (traficante de drogas) um imóvel pago por meio de US $\$ 182.500,00$, sendo US $\$ 60.000,00$ pagos "por fora" em dinheiro e em pequenos pacotes de compras, e escriturando o bem pela diferença. Consta que nos encontros realizados entre Campbell e Lawing, o cliente aparecia sempre com veículos de luxo, e certa vez teria mostrado US\$ 20.000,00 em espécie à vendedora, como forma de comprovar seu poder aquisitivo. Uma das testemunhas relatou que a acusada teria declarado que o dinheiro poderia ser proveniente de drogas. Campbell foi condenada pelo júri, sob o fundamento que teria "fechado os olhos", deliberadamente, para o que, de outra maneira lhe seria óbvio. Sua condenação foi revista pela Corte Distrital, mas, em apelação ao $4^{\circ}$ Circuito, a decisão do júri foi mantida, diante da demonstração de que, apesar de a acusada não ter agido com o propósito específico de lavar o dinheiro originário do tráfico, tinha o interesse em fechar o negócio e coletar sua comissão, não importando a fonte do numerário. Como refere parte da sentença, questão relevante no caso não é o propósito de Campbell, mas sim seu conhecimento a respeito do propósito de Lawing.
\end{abstract}

Ainda, de acordo com Moro, permissivo salientar que em relação ao Willful Blindness Doctrine, a referida doutrina da teoria da cegueira deliberada tem sido aceita pelos Tribunais dos Estados Unidos da América (EUA) nas seguintes hipóteses, a saber: a) primeiramente, quando existe prova que caminhe no sentido de que o agente tinha conhecimento da elevada probabilidade de que os bens, direitos ou valores envolvidos eram provenientes de crime, e, b) que o agente agiu de modo indiferente a esse conhecimento (2010).

O mesmo autor é enfático ao salientar ainda que, em algumas Cortes dos EUA, o que se observa é que se tem exigido que a relação de indiferença com a possibilidade de conhecimento do fato delituoso seja demonstrada por meio de prova de que o agente tenha, de forma deliberada, optado por permanecer na ignorância quanto aos fatos, quando havia possibilidade de conhecimento.

Como pudemos analisar, Moro admite a plena aplicação da teoria da cegueira deliberada (Wilfull Blindness Doctrine) quando o judiciário estiver à frente de crimes envolvendo delito de lavagem de capitais, à guisa de exemplo.

Curioso e extremamente relevante o fato de que Ricardo (2018), faz referência a Moro, enquanto estava na titularidade da $13^{\mathrm{a}}$ Vara Criminal de Curitiba, à frente do emblemático caso envolvendo a Operação Lava-Jato. Nas palavras de Ricardo (2018, p. 245), podemos destacar que:

Mais recentemente, a Willful Blindness Doctrine vem ganhando força, em especial, perante a $13^{\mathrm{a}}$ Vara Criminal Federal de Curitiba, seção judiciária do 
Paraná, sob a titularidade do Juiz Federal Sérgio Fernando Moro, magistrado que está à frente da denominada "Operação Lava Jato". Como se sabe, o conjunto de crimes que compõe a "Lava Jato", a maioria já objeto de ações penais, são de competência da Justiça Federal, em decorrência da presença de diversos crimes federais. A competência da $13^{\mathrm{a}}$ Vara Federal de Curitiba para os crimes apurados e em apuração na referida operação decorre das regras processuais penais de conexão e continência, tendo em vista que aquele juízo tornou-se prevento quando da origem da investigação, lavagem consumada em Londrina/PR, assim como nos termos do artigo 71 do Código de Processo Penal.

Ainda, segundo Ricardo (2018), a operação lava-jato durou três anos e gerou diversas ações penais. Para o Ministério Público Federal, de acordo com os levantamentos de Ricardo (2018, p. 246), pode-se destacar que a Operação Lava-Jato pode ser considerada como:

\begin{abstract}
A maior investigação de corrupção e lavagem de dinheiro que o Brasil já teve. Estima-se que o volume de recursos desviados dos cofres da Petrobras, maior estatal do país, esteja na casa de bilhões de reais. Soma-se a isso a expressão econômica e política dos suspeitos de participar do esquema de corrupção que envolve a companhia. No primeiro momento da investigação, desenvolvido a partir de março de 2014, perante a Justiça Federal em Curitiba, foram investigadas e processadas quatro organizações criminosas lideradas por doleiros, que são operadores do mercado paralelo de câmbio. Depois, o Ministério Público Federal recolheu provas de um imenso esquema criminoso de corrupção envolvendo a Petrobras. Nesse esquema, que dura pelo menos dez anos, grandes empreiteiras organizadas em cartel pagavam propina para altos executivos da estatal e outros agentes públicos. $\mathrm{O}$ valor da propina variava de $1 \%$ a $5 \%$ do montante total de contratos bilionários superfaturados. Esse suborno era distribuído por meio de operadores financeiros do esquema, incluindo doleiros investigados na primeira etapa.
\end{abstract}

Nesta ótica, a aplicação da teoria da cegueira deliberada conseguiu responsabilizar mais envolvidos utilizando-se dessa doutrina em alinhamento com o dolo eventual.

Em posicionamento antagônico, para Valente (2017), especificamente no que se refere a aplicabilidade da teoria da cegueira deliberada, mister se faz seja estabelecida uma relação entre o direito penal e o direito constitucional, na perspectiva de um suposto "princípio da proporcionalidade" que deve seguir algumas características, a saber:

[...](a) a teoria não será aplicada aos crimes de menor potencialidade lesiva; (b) deve ser determinado, a partir das circunstâncias do evento delituoso, se tinha o agente condições ou meios de ter conhecimento acerca do caráter antijurídico de sua conduta e que, em razão disso, agiu deliberadamente para dificultar seu próprio entendimento; e (c) deve o bem jurídico ser penalmente tutelado, guardando pertinência com a ordem constitucional, máxime com os princípios da intervenção mínima e da fragmentariedade. Por exemplo, é comum que, em se tratando de lavagem de capitais, o autor, fingindo desconhecimento, coloca-se em situação de ignorância acerca dos bens, 
direitos e valores provenientes, direta ou indiretamente, da infração penal antecedente (crime periférico), a fim de se elidir da responsabilidade criminal e não responder pelo crime capitulado no artigo $1^{\circ}$ da Lei 9.613/1998, com alteração trazida pela Lei 12.683/2012 (VALENTE, 2017, não paginado).

Para o mesmo Autor, revela-se preocupante a mera aplicação desta teoria sem que sejam tomados alguns cuidados, em especial ao pontificar que:

Portanto, a hermenêutica penal não deve se restringir, por ora, à mera menção ou construção da cegueira deliberada, mas deve se voltar à sua desconstrução à luz do direito penal liberal, sob pena de "improbidade epistêmica" e de um desmesurado ativismo judicial (Valente, 2017, não paginado).

Destarte, a dialética por parte da doutrina apresentada acima reflete posicionamentos relevantíssimos ora pela aplicação da teoria da cegueira deliberada, ora negam a utilização desta doutrina no meio forense, o que reforça o aprofundamento do tema para a comunidade científica.

Após todos os tópicos apresentados neste artigo, é relevante destacarmos que a doutrina da teoria da cegueira deliberada não possui tipificação legal, sendo fruto de construção doutrinária e jurisprudencial.

\section{CONSIDERAÇÕES FINAIS}

A conclusão é a de que existe profunda preocupação da doutrina a respeito da aplicabilidade da teoria da cegueira deliberada, porquanto como analisado ao longo deste artigo, para certos tipos penais existe doutrina balizada favorável à utilização no ordenamento jurídico brasileiro.

Para Valente a aplicação da aludida teoria no meio forense necessita de um maior refinamento por parte da doutrina, afirmando que seja estabelecida uma relação entre o direito penal e o direito constitucional, na perspectiva de um suposto "princípio da proporcionalidade" que deve seguir algumas características, quando tratamos da teoria da cegueira deliberada no brasil: surgimento e controvérsias doutrinárias.

Por outro lado, a contribuição para a comunidade científica residiu em fazermos um resgate histórico a respeito do surgimento da teoria da cegueira deliberada no ordenamento jurídico brasileiro, adotando-se o caso do assalto ao Banco Central do Brasil, na cidade de Fortaleza. 
É nesta conjugação entre o direito comparado e o nosso ordenamento jurídico que se permite a evolução do direito penal brasileiro numa perspectiva que vise a real conduta do agente para fins de aplicação ou não da doutrina da teoria da cegueira deliberada, como procuramos salientar nos casos analisados e citados ao longo deste despretensioso estudo.

\section{REFERÊNCIAS}

ANDREUCCI, Ricardo Antonio. Manual de direito penal. 8. ed. rev. São Paulo: Saraiva,2012.

BARROS, Flávio Augusto Monteiro de. Direito penal, parte geral: v. 1. 7. ed. São Paulo: Saraiva,

BIERRENBACH, Sheila. Teoria do crime. Rio de Janeiro: Editora Lumen Juris, 2009.

BITENCOURT, Cezar Roberto. Tratado de Direito Penal, volume 1: parte geral. 16. ed. São Paulo: Saraiva, 2011.

BRANDÃO, Claudio. Curso de direito penal: parte geral. 2. ed. Rio de Janeiro: Forense, 2010.

BUSATO, Paulo César. Direito penal, parte geral. São Paulo: Atlas. No prelo. BUSATO, Paulo César; DÍAZ PITA, María del Mar; MARTÍNEZ-BUJÁN PÉREZ, Carlos. Modernas tendências sobre o dolo em direito penal. Rio de Janeiro: Lumen Juris, 2008.

CAPEZ, Fernando. Curso de direito penal, volume 1, parte geral. 15. ed. São Paulo: Saraiva. 2011.

CARDOSO, Francisco de Assis Machado. Leis Penais Especiais. Editora Juspodivm, Salvador, 2018, p. 1.350 .

CARVALHO, Hermínia Geraldina Ferreira de. A (anacrônica) importação da doutrina da cegueira deliberada pela jurisprudência brasileira: incompatibilidade lógica entre a teoria norte-americana causalista e o tratamento do erro de tipo no modelo finalista de ação. Disponível em:< https://www.academia.edu/15299373/A_ANACR\%C3\%94NICA_IMPORTA\%C3\%87\%C3 \%830_DA_DOUTRINA_DA_CEGUEIRA_DELIBERADA_PELA_JURISPRUD\%C3\%8A NCIA_BRASILEIRA_INCOMPATIBILIDADE_L\%C3\%93GICA_ENTRE_A_TEORIA_N ORTE-

AMERICANA_CAUSALISTA_E_O_TRATAMENTO_DO_ERRO_DE_TIPO_NO_MODE LO_FINALISTA_DE_A\%C3\%87\%C3\%83O>. Acesso em: 14. fev. 2020. 
COSTA JR., Paulo José da. Curso de direito penal. 12. ed. rev. São Paulo: Saraiva, 2010. DÍAZ PITA, María del Mar. El dolo eventual. Valencia: Tirant lo Blanch, 1994.

DOTTI, René Ariel. Curso de direito penal: parte geral. 3. ed. rev. São Paulo: Editora Revista dos Tribunais, 2010.

DOTTI, René Ariel. Nova definição legal do dolo eventual. Disponível em:< https://www.migalhas.com.br/depeso/151307/nova-definicao-legal-do-dolo-eventual>.

Acesso em: 15. fev. 2020.

ESTEFAM, André. Direito penal, volume 1. São Paulo: Saraiva, 2010.

FILIPPETTO, Rogério. Lavagem de dinheiro: crime econômico da pós-modernidade. Rio de Janeiro: Lumen 2011.

FRANCO, Alberto Silva. Código penal e sua interpretação: doutrina e jurisprudência. 8.ed. São Paulo: Editora Revista dos 2007.

GOMES, Luiz Flávio. Direito penal: parte geral. São Paulo: Editora Revista dos Tribunais, 2007.

GEHR, Amanda. A aplicação da teoria da cegueira deliberada no direito penal brasileiro. Disponível $\quad$ em:< https://acervodigital.ufpr.br/bitstream/handle/1884/31107/AMANDA\%20GEHR.pdf?sequen> . Acesso em: 08. jan. 2020.

GRECO, Rogério. Curso de direito penal. 13. ed. Rio de Janeiro: Impetus, 2011.

GUARAGNI, Fábio André. As teorias da conduta em direito penal: um estudo da conduta humana do pré-causalismo ao funcionalismo pós-finalista. São Paulo: Editora Revista dos Tribunais, 2005.

HASSEMER, Winfried. Persona, mundo y responsabilidade. Valencia: Tirant lo Blanch, 1999.

ISHIDA, Válter Kenji. Curso de direito penal. 2. ed. São Paulo: Atlas, 2010.

JESUS, Damásio de. Direito penal, volume 1: parte geral. 32. ed. São Paulo: Saraiva, 2011.

LAUFER, Christian. "Breves considerações sobre o instituto da ignorância deliberada". Universidade Federal do Paraná, Programa de Pós Graduação em Direito, Mestrado em

Direito, 2010. 
LAURENZO COPELLO, Patricia. Dolo y conocimiento. Valencia: Tirant lo Blanch, 1999. MARTÍNEZ BUJÁN-PÉREZ, Carlos. Derecho penal económico y de la empresa, parte general. 2. ed. Valencia: Tirant lo Blanch, 2007.

MIRABETE, Julio Fabbrini. Manual de direito penal, volume 1: parte geral, arts. $1^{\circ}$ a 120 do CP. 28. ed. rev. São Paulo: Atlas, 2012. MOMMSEN, Teodoro. Derecho penal romano. Bogotá: Temis, 1976. MORO, Sérgio Fernando. Crime de lavagem de dinheiro. São Paulo: Saraiva, 2010.

MOSER, Manoela Pereira. A teoria da cegueira deliberada no direito penal econômico. Revista de doutrina e jurisprudência. Brasília, 108. p. 166-182/ jan-jul, 2017.

NUCCI, Guilherme de Souza. Manual de direito penal. 7. ed. rev. São Paulo: Editora Revista dos

Tribunais,

2011.

PRADO, Luiz Regis. Curso de direito penal brasileiro, volume 1: parte geral, arts. $1^{\circ}$ a 120. 7. ed. rev. São Paulo: Editora Revista dos Tribunais, 2007.

PRADO, Rodrigo Leite. Dos crimes: aspectos subjetivos. In Lavagem de dinheiro: prevenção e controle penal. DI CARLI, Carla Veríssimo (coord.). Porto Alegre: Verbo Jurídico, 2011.

PUPPE, Ingeborg. A distinção entre dolo e culpa. Barueri: Manole, 2004. RAGUÉS I VALLÈS, Ramon. La ignorancia deliberada en derecho penal. Barcelona: Editora Atelier, 2007.

RICARDO, Lucas Nacur Almeida. Teoria da Cegueira deliberada: reflexões sobre sua aplicação aos crimes de lavagem de capitais. De Jure, v. 17, n. 30, jan-jun., 2018, p. 233-259. Disponível em:< De Jure | ISSN 1809-8487 | v. 17 |n. 30 |jan.-jun. 2018 |p. 233-259>. Acesso em: 14. Fev. 2020.

ROBBINS, Ira P. The ostrich instruction: deliberate ignorance as a criminal mens rea. The Journal of Criminal Law Criminology. Northwestern University School of Law, USA, v. 81, Summer 1990, p. 191- 234.

RODRÍGUEZ, Victor Gabriel. Fundamentos do direito penal brasileiro: lei penal e teoria $\begin{array}{llllll}\text { geral do } & \text { crime. } & \text { São } & \text { Paulo: } & \text { Atlas, } & \end{array}$

ROXIN, Claus. Funcionalismo e imputação objetiva no direito penal. 3. Ed. Rio de Janeiro: Renovar, 2002.

SANTOS, Juarez Cirino dos. Direito penal - parte geral. 2. ed. Curitiba: Lumen Juris, 2007. 
VALENTE, Victor Augusto Estevam. Aplicação da cegueira deliberada requer cuidados na prática forense. Consultor Jurídico. Disponível em: $<$ https://www.conjur.com.br/2017-ago09/victor-valente-aplicacao-cegueira-deliberada-requer-cuidados >. Acesso em: 12. fev. 2020.

ZAFFARONI, Eugênio Raul, PIERANGELI, José Henrique. Manual de Direito Penal Brasileiro: parte geral. 6. Ed. São Paulo: Revista dos Tribunais, 2006, p. 600. 